\title{
Vulnerability to COVID-19 in Pernambuco, Brazil: A geospatial evaluation supported by multiple-criteria decision aid methodology
}

\author{
Ciro José Jardim de Figueiredo, ${ }^{1}$ Caroline Maria de Miranda Mota ${ }^{2}$ Amanda Gadelha Ferreira \\ Rosa, ${ }^{2}$ Arthur Pimentel Gomes de Souza, ${ }^{2}$ Simone Maria da Silva Lima ${ }^{2}$ \\ ${ }^{1}$ Department of Engineering, Federal Rural University of the Semi-Arid, Angicos, RN; ${ }^{2}$ Department of \\ Production Engineering, Federal University of Pernambuco, Recife, PE, Brazil
}

\begin{abstract}
The paper presents an innovative application to identify areas vulnerable to coronavirus disease 2019 (COVID-19) considering a combination of spatial analysis and a multi-criteria learning approach. We applied this methodology in the state of Pernambuco, Brazil identifying vulnerable areas by considering a set of determinants and risk factors for COVID-19, including demographic, economic and spatial characteristics and the number of human COVID-19 infections. Examining possible patterns over a set number of days taking the number of cases recorded, we arrived at a set of compatible decision rules to explain the relation between risk factors and COVID-19 cases. The results reveal why certain municipalities are critically vulnerable to COVID-19 highlighting locations for which knowledge can be gained about environmental factors.
\end{abstract}

Correspondence: Ciro José Jardim de Figueiredo, Department of Engineering, Federal Rural University of the Semi-Arid, Rua Gamaliel Martins Bezerra, s/n - Alto da Alegria, Angicos, RN, Brazil. E-mail: ciro.figueiredo@ufersa.edu.br

Key words: COVID-19; multiple criteria; geographical information system; vulnerability analysis; Brazil.

Funding: this study was financed in part by the Conselho Nacional de Desenvolvimento Científico e Tecnológico (CNPQ) and the Fundação de Amparo à Ciência e Tecnologia de Pernambuco (FACEPE).

Conflict of interest: the authors declare no potential conflict of interest.

Received for publication: 24 March 2021.

Revision received: 7 July 2021

Accepted for publication: 8 July 2021.

(C) Copyright: the Author(s), 2022

Licensee PAGEPress, Italy

Geospatial Health 2022; 17(s1):1000

doi:10.4081/gh.2022.1000

This article is distributed under the terms of the Creative Commons Attribution Noncommercial License (CC BY-NC 4.0) which permits any noncommercial use, distribution, and reproduction in any medium, provided the original author(s) and source are credited.

\section{Introduction}

The world is experiencing a pandemic caused by the severe acute respiratory syndrome-related coronavirus 2 (SARS-CoV-2) a new, highly contagious virus, which causes the coronavirus disease 2019 (COVID-19). In response to this situation, several studies have sought to understand patterns of how COVID-19 spreads through communities exploring different forms of response and prevention. The need to rapidly place the COVID-19 pandemic in context motivated the interest in research by applying spatial visualization with special spotlight tools, such as dynamic maps (WHO, 2020) as well as prediction models of the infection's dispersal over time (Souza et al., 2020). The advantage of producing vulnerability maps means that places that have been subject to previous pandemics and their risks (UNISDR, 2009; Hazarika et al., 2018) can be identified in addition to a multidimensional comprehension of social, economic, ecological and geographical factors. However, there are many aspects related to the current context (Adger, 2006; Younsi et al., 2020), which led us to construct a decision-learning model to identify areas vulnerable to COVID19 using, simultaneously, demographic variables associated with the occurrence of the disease, including space characteristics and transmission dynamics.

Models dealing with the transmission of infectious diseases have been developed to understand the dynamics of transmission and to explore relationship with environmental, social and economic factors. Two of the best-known models use the basic reproduction number $\mathrm{R}_{0}$ to make evaluations over a time span based on compartmental models to predict the size and duration of outbreaks, e.g. the 'susceptible - exposed-infected-removed (SEIR)' chain (Getz et al., 2018) or the 'susceptible - infected-recovered (SIR)' approach (Ball and Neal, 2002). Since then, alternative ways have been developed to deal mathematically with transmission and prediction of virus spread in a geographical area. Ambikapathy and Krishnamurthy (2020) built a model based on first-order, ordinary differential equations to describe how different lockdown scenarios would impact the number of COVID-19 infected cases in India. Others focused on the determinants governing the spread of the SARS-CoV-2 in order to prevent this occurring in the future, e.g. Qiu et al (2020) investigated the relationship between confirmed cases and factors, such as population density, population flow, the gross domestic product (GDP) per capita, the number of doctors at the city level as well as meteorological variables. Pre-existing diseases in people and places have also been shown to affect those vulnerable to SARS-CoV-2 infection (Du et al., 2020; Edler et al., 2020; Qi et al., 2020; Yang et al., 2020).

The aim of geographical information systems (GIS) is to 
reveal spatial patterns of events in a given area and the network dynamic involved, and this approach can therefore assist by indicating places that are vulnerable due to certain characteristics (De Toro et al., 2020). Several GIS applications with respect to the context of the ongoing COVID-19 pandemic can be found in health-related studies. For example, Kim and Bostwick (2020) conducted a hotspot analysis that identified clusters of COVID-19 deaths, a social vulnerability index, a health risk score and the racial composition of the deceased. Although the GIS framework based on a multiple-criteria decision aid (MCDA) would have a great practical value, there are only a few such studies supporting decisions on communicable diseases. Li et al. (2007) built a model to evaluate the pathogenic spread of influenza, whereas Stevens et al. (2013) identified areas in Asia prone to occurrence of the pathogenic influenza virus (H5N1). Dom et al. (2016) developed a spatial tool combined with the analytic hierarchy process (AHP) to support assessing the risk of dengue. Younsi et al. (2018) introduced a spatiotemporal system based on what they called a 'preference ranking organization method for enrichment of evaluation' (PROMETHEE)-II to monitor and map potential high-risk areas of seasonal influenza and other diseases. Fusade-Boyer et al. (2020) applied the AHP method to weigh the risk factors to the delta influenza virus (that causes influenza D) for posterior aggregation and map visualization, while Younsi et al. (2020) used decision rules to evaluate the risk of seasonal influenza.

Hongoh et al. (2011) emphasize the importance of maps in identifying the spatial distribution of disease determinants and how this aids public health policies. Following this approach, our study presents a structured model implementation based on GIS-MCDA as this made it possible to integrate mapping analysis and multiplecriteria analysis. We developed a decision model within a GIS framework based the MCDA to identify areas particularly vulnerable to COVID-19 in the state of Pernambuco, Brazil. The model integrates a spatial analysis and a decision-rule procedure in order to reveal vulnerable municipalities. This requires a structural, spatial analysis of vulnerability based on demographic data and recorded cases of COVID-19, and it highlights locations and provides information that should help health staff determine what public policies to apply.

\section{Materials and methods}

We investigated the association between environmental factors, here a set of social, economic and demographic variables, against the occurrence of COVID-19 and used this information to build a decision-making model to pinpoint vulnerable areas. The model sorts areas into three classes of vulnerability: low $\left(\mathrm{Cl}_{1}\right)$; moderate $\left(\mathrm{Cl}_{2}\right)$; and high $\left(\mathrm{Cl}_{3}\right)$. Importantly, we did not seek to predict where COVID-19 cases will occur, but where preventive actions should be applied.

\section{Study site}

The study comprised the whole state of Pernambuco in northeastern Brazil with its 185 municipalities (Figure 1). According to the Institute of Geography and Statistics (Instituto Brasileiro de Geografia e Estatística - IBGE), its 9 million inhabitants make the state the seventh most populous among the 26 Brazilian states (IBGE, 2020). Together with 14 other municipalities, the state capital Recife forms the Metropolitan Region of Recife (MRR) with approximately 4 million inhabitants. Located close to the MRR, Caruaru has 360,000 inhabitants and is the second largest urban municipality and Petrolina is the third (350,000 inhabitants). Both municipalities provide services to neighbouring municipalities. Fernando de Noronha Island, an archipelago of 21 islands and islets, was excluded from the study due to its special status as marine national park.
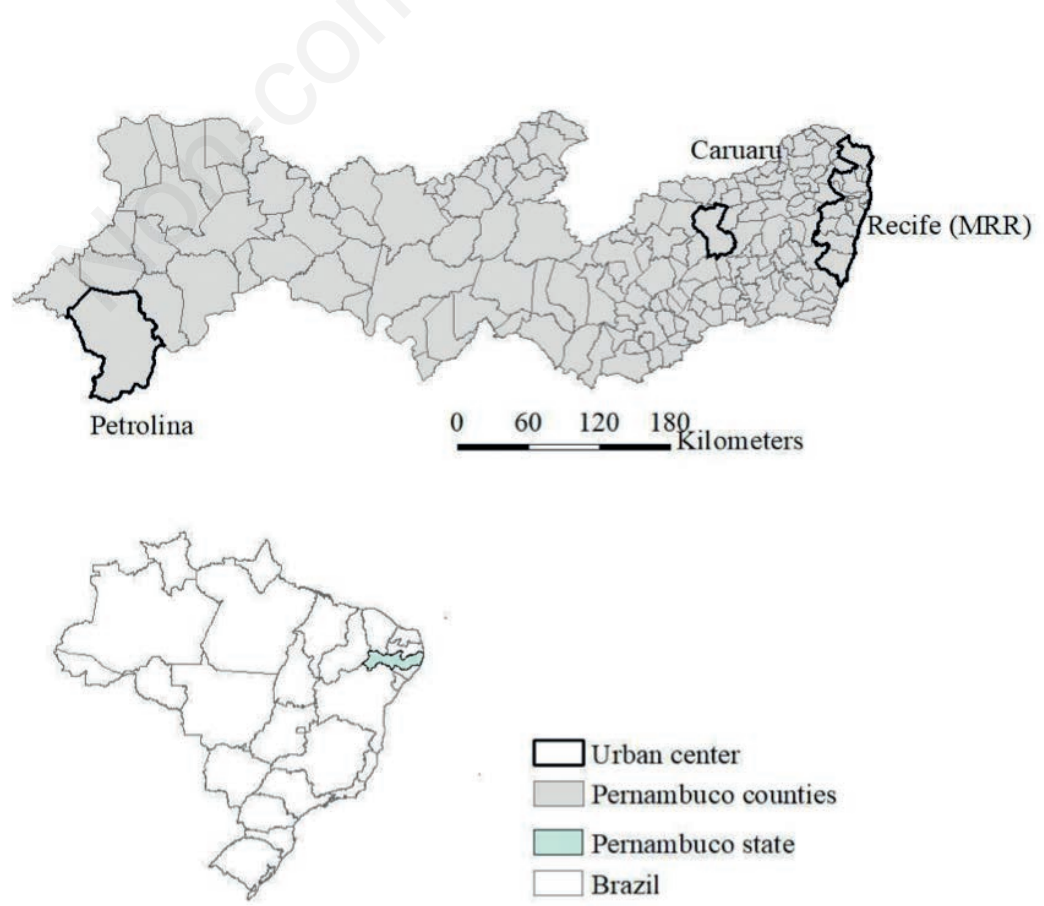

Urban center

Pernambuco counties

Pernambuco state

Brazil

Figure 1. Location of Pernambuco and its municipalities. 


\section{Spatial analysis}

The proposed GIS-MCDA methodology is divided into three stages as illustrated in Figure 2. The first involves defining the characteristics of the municipalities of Pernambuco by gathering primary data and exploring the factors that may be related to COVID-19. This stage is confirmatory for correlate variables (attributes) and COVID-19 cases, thereby establishing a spatial association. Thus, spatial data analysis was used to map confirmed cases, and geographically weighted regression (GRW) as described by Fotheringham et al. (2002) was applied to verify the relation between spatial features and the recorded COVID-19 cases. We also examined the potential spatial autocorrelation to identify spatial clusters of the infection.

The second stage comprises building the GIS-MCDA model, which considers available knowledge associated with a reference map (or table). The model is based on the Preference Learning Dominance-based Rough Set Approach (PL-DRSA) (Figueiredo and Mota, 2019), where several subsets of reference objects (ROs) are built to train (learn) vulnerability classification rules. The preferences are represented by a set of decision rules of the type 'if..., then...', that assign objects (areas) to (unions of) classes of vulnerability that we applied to the municipalities.

In the third stage, the rules are examined and then applied to classify all objects of the study area leading to the establishment of a regional map of vulnerability to COVID-19. This map was used to identify the municipalities that need to implement more restrictive actions. The decision rules assist the understanding which characteristics may lead to a municipality being more vulnerable than another, and how it can best avoid the emergence of new cases. For each category, a set of adopted strategies, e.g. imple- menting social distancing and imposing lockdown, was repeated to update a learning map and the decision rules taking the dynamic aspects of COVID-19 distribution over time into account. The spatial analysis was executed using ArcGIS 10.4.1 software (ESRI, 2011), while the DRSA evaluations were performed using the jMAF platform (Blaszczynski et al., 2013), a 'Rough Set Data Analysis Framework' (available from: http://idss.cs.put. poznan.pl/site/139.html).

In spatial analysis, several tools are available to gain a better understanding of the behaviour of the spatial variables. GWR, a non-parametric model with spatially variable coefficients, can often produce improved models that consider spatial autocorrelation of the determinants, thus enabling spatial inference. GWR was designed to investigate the quantitative relationship between two or more variables with spatial distribution characteristics and is mathematically described as:

$y_{i}=\beta_{0}\left(u_{i}, v_{i}\right)+\sum_{k=1}^{N} \beta_{k}\left(u_{i}, v_{i}\right) x_{k, i}+e_{i}$

where $y_{i}$ is the dependent variable at $i^{\text {th }}$ alternatives in space; $\beta_{0}$ and $\beta_{k}$ the estimated coefficients; $\left(u_{i}, v_{i}\right)$ the vector coordinates of $i^{\text {th }}$ alternatives in space; $x_{k, i}$ the $k^{\text {th }}$ explanatory variables at $i^{\text {th }}$ alternatives in space; and $e_{i}$ the random error term at the $i^{\text {th }}$ alternative in space.

The goodness of fit of GWR models was evaluated by means of adjusted $R^{2}$ (a version of $R^{2}$ that indicates that added input variables are unimportant for the outcome), Akaike's information criterion (AIC) and residuals. The correlation in the residuals was inspected by calculating correlograms displaying Moran's I (Moran, 1950) of the residuals against distance as e.g. done by Sá

Identifying environmental risk factors for COVID-19

Exploring studied area, delimitation and spatial units

Spatial analysis (IDW) and associations by OLS and GWR

Stage 1

Risk factors

Modeling a GIS-MCDA based on PL-DRSA

Establishing the set of condition attributes and the decision attribute (vulnerability)

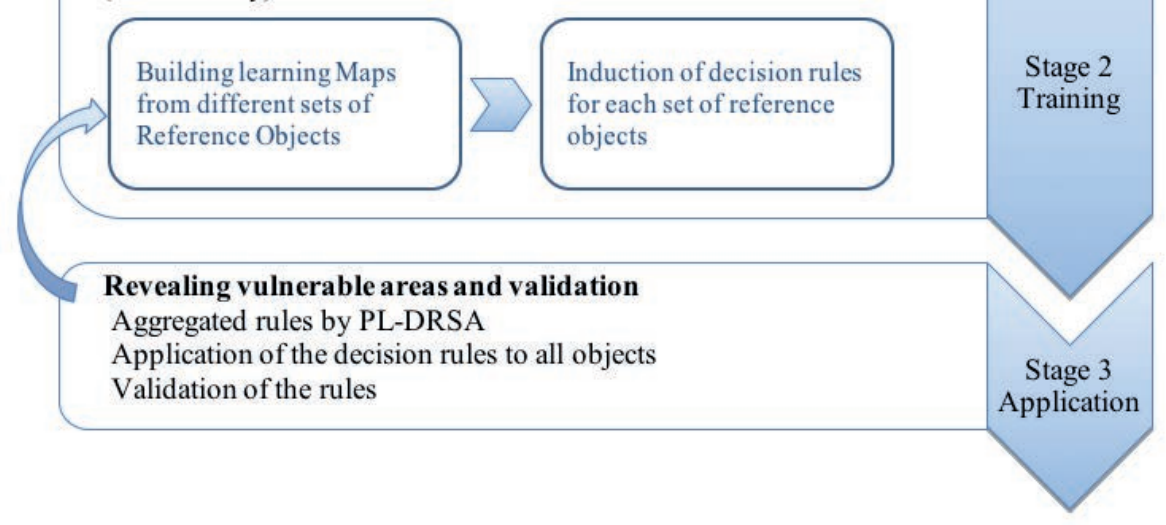

Figure 2. Steps of the geographical information system-multiple-criteria decision aid (GIS-MCDA) methodology. IDW, inverse distance weighting; OLS, ordinary least squares; GWR, geographically-weighted regression; PL-DRSA, preference learning dominance-based rough set approach. 
et al. (2011). Moran's I of the spatial autocorrelation was used to measure the degree of similarity between samples for a given variable due to spatial distance (Sá et al., 2011; Li et al., 2020).

Inverse distance weighting (IDW), another spatial statistic, has been extensively applied to predict values for any unmeasured locations, where it uses the values measured surrounding the location for which a prediction is needed. IDW interpolation explicitly assumes that things that are close to one another are more alike than those that are farther apart according to Tobler's law of 1970 (Watson and Philip, 1985). The formula of IDW takes this form:

$$
Z^{*}\left(x_{0}\right)=\frac{\sum_{i=1}^{n} z\left(x_{i}\right) d_{i j}^{-r}}{\sum_{i=1}^{n} d_{i j}^{-r}}
$$

where $Z^{*}\left(x_{0}\right)$ is the predicted variables at sampling site $x_{0} ; x_{i}$ the data points within the chosen area; $d_{i j}$ the distance between the predicted point and the data points; and $r$ the weight related to distance by $d_{i j}$.

\section{The dominance-based rough set approach}

Each DRSA application (Greco et al., 2002, 2013; 2016) is based on a data table formally represented by a quadruple information system $S=\{A, Q, V, f\}$, where $A=$ a 'non-empty' finite set of objects (ROs); $Q=$ a 'non-empty' finite set of attributes; $V=$ $\mathrm{U}_{q \in Q} V_{q}$ (where $V_{q}$ is a domain of the attribute ${ }_{q}$ ); and $f: A \times Q \rightarrow V$ $=$ a total function defined such that $f(a, q) \in V_{q}$ for each attribute $q \in Q$ and object $a \in A$. The set $Q$ is often divided into a sub-set $C$ $=\left\{c_{1}, c_{2}, \ldots, c_{m}\right\}$ of conditional attributes with $C \neq \varnothing$ and a subset $D$ $\neq \varnothing$ of decision attributes, such that $C \mathrm{U} D=Q$ and $C \cap D \neq \varnothing$. Moreover, the ROs are considered learning objects due their ability to become updated based on the addition of new objects.

The DRSA is enriched by introducing an outranking relation $\succcurlyeq_{\mathrm{c}}$ into $A^{*}$ with respect to attribute $c \in C$, such that $\mathrm{a}_{1}{ }^{*} \geqslant_{\mathrm{c}} a_{2}{ }^{*}$ means that $\mathrm{a}_{1}{ }^{*}$ is at least as good as $\mathrm{a}_{2}{ }^{*}$ with respect to attribute $c$, for the sake of simplicity hereafter considered the case of a single decision attribute, i.e. $D=\{d\}$ is. More formally, let $C l=\{C l, t \in\{1, \ldots$ $, n\}$, be a set of classes of $A$ such that each $a_{1}{ }^{*} \in A$ belongs to one and only one class $C l_{t} \in C l$. Suppose that $C l_{r}$ and $C l_{s}$ are two predefined classes with $r, s \in T, \mathrm{a}_{1}{ }^{*} \in C l_{r}$ and $a_{2}{ }^{*} \in C l_{s}$. If $r>s$, then $a_{1}{ }^{*} \geqslant a_{2}{ }^{*}$. DRSA introduces the concept of an approximation of a set of objects (or union of decision classes) with respect to a set of attributes (or criteria). These are called the upward and downward union decision classes defined as: $\mathrm{Cl}_{t}^{\geq}$and $\mathrm{Cl}_{t}^{\leq}$. A monotonic relationship with the decision class is assumed for each evaluation, and the dominance relation is defined. Let $P \subseteq C$ be a subset of the condition attribute. It is said that $a_{1}{ }^{*}$ dominates $a_{2}{ }^{*}$ in the conditionattribute space (denoted by $a_{1}{ }^{*} D_{p} a_{2}{ }^{*}$ ) if $a_{1}{ }^{*} \geqslant_{\mathrm{c}} a_{2}{ }^{*} \forall \mathrm{c} \in \mathrm{P}$. Let $D_{p}{ }^{+}$ $\left(a_{1}{ }^{*}\right)$ be the set of objects dominating $a_{1}{ }^{*}$ and $D_{p}{ }^{-}\left(a_{1}{ }^{*}\right)$ be the set of objects dominated by $a_{1}{ }^{*}$, which are defined as:

$$
\begin{aligned}
& D_{p}^{+}\left(a_{1}^{*}\right)=\left\{a_{2}^{*} \in A^{*}: a_{2}^{*} D_{p} a_{1}^{*}\right\} \\
& D_{p}^{-}\left(a_{1}^{*}\right)=\left\{a_{2}^{*} \in A^{*}: a_{1}^{*} D_{p} a_{2}^{*}\right\}
\end{aligned}
$$

For $P \subseteq C$, the collection of all objects that can be classified as $\mathrm{Cl}_{t}^{\geq}$and $\mathrm{Cl}_{t}^{\leq}$without any ambiguity constitutes the $P$-upper approximation of $\mathrm{Cl}_{t}^{\geq}$(least classification) and $\mathrm{Cl}_{t}^{\leq}$(most classifi- cation). Analogously, one can define the $P$-lower approximation of $\mathrm{Cl}_{t}^{\geq}$and $\mathrm{Cl}_{t}^{\leq}$with ambiguity These collections are denoted as follows:

$$
\begin{aligned}
& \text { The } P \text {-upper approximation of } C l_{t}^{2}: \underline{P}\left(C l_{t}^{2}\right)=\left\{a_{1}^{*} \in A^{*}: D_{\bar{P}}^{-}\left(a_{1}^{*}\right) \cap C l_{t}^{2} \neq \emptyset\right\} \\
& \text { The } P \text {-lower approximation of } C l_{t}^{2}: \underline{P}\left(C l_{t}^{2}\right)=\left\{a_{1}^{*} \in A^{*}: D_{P}^{+}\left(a_{1}^{*}\right) \subseteq C l_{t}^{2}\right\} \\
& \text { The } P \text {-upper approximation of } C l_{t}^{s}: \underline{P}\left(C l_{t}^{s}\right)=\left\{a_{1}^{*} \in A^{*}: D_{P}^{+}\left(a_{1}^{*}\right) \cap C l_{t}^{s} \neq \emptyset\right\} \mid \\
& \text { The } P \text {-lower approximation of } C l_{t}^{\leq}: \underline{P}\left(C l_{t}^{\leq}\right)=\left\{a_{1}^{*} \in A^{*}: D_{\bar{P}}^{-}\left(a_{1}^{*}\right) \subseteq C l_{t}^{\leq}\right\}
\end{aligned}
$$

All objects that are classified as $\mathrm{Cl}_{t}^{\geq}$and $\mathrm{Cl}_{t}^{\leq}$with some ambiguities constitute the $P$-boundaries ( $P$-doubtful regions) of $\mathrm{Cl}_{t}^{\geq}$and $\mathrm{Cl}_{t}^{\leq} . \mathrm{Bn}_{P}\left(\mathrm{Cl}_{t}^{\geq}\right)=\underline{P}\left(\mathrm{Cl}_{t}^{\geq}\right)-\underline{P}\left(\mathrm{Cl}_{t}^{\geq}\right), \mathrm{Bn}_{P}\left(\mathrm{Cl}_{t}^{\leq}\right)=\underline{P}\left(\mathrm{Cl}_{t}^{\leq}\right)-\underline{P}\left(\mathrm{Cl}_{t}^{\leq}\right)$, $t=\{1, \ldots n\}$. For every $P \subseteq C$, the quality of approximation of the ordinal classification $\mathrm{Cl}$ by the set of attributes is considered to be the ratio expressed by the cardinality between the universe $A$ and all $P$-correctly classified alternatives:

$$
\gamma_{P}(C l)=\frac{\left|A-\left(\mathrm{U}_{t=1, \ldots, n} B n_{P}\left(C l_{t}^{\zeta}\right)\right) \cup\left(\mathrm{U}_{t=1, \ldots, n} B n_{P}\left(c l_{t}^{\gtrless}\right)\right)\right|}{|A|}
$$

where $\gamma_{P}(\mathrm{Cl})$ can be seen as a degree of consistency of the objects from $A$, where $P$ is the set of attributes and $C l$ is the ordinal classification considered. Every minimal subset $P \subseteq C$, such that $\gamma_{P}(C l)=$ $\gamma_{c}(C l)$, is called a reduct of $C$ with respect to $C l$ and is denoted by $\operatorname{RED}_{\mathrm{Cl}}(\mathrm{P})$. A data table may have more than one reduct, such that the intersection of all of the reducts is the core, which is denoted by $C O R E_{C l}$.

These approximations are explored to induce decision rules of the type 'if ..., then...' used to assign the objects into unions of classes $\mathrm{Cl}_{t}^{\geq}$and $\mathrm{Cl}_{t}^{\leq}$. According to Greco et al. (2002), five types of decision rules may be considered: i) certain $D_{\geq}$-decision rules generated from the lower approximation $\underline{P}\left(C l_{t}^{\geq}\right)$; ii) possible $D_{\geq}$decision rules generated from the upper approximation $\underline{P}\left(\mathrm{Cl}_{t}^{\geq}\right)$, with or without any ambiguity; iii) certain $D_{\leq}$-decision rules generated from $\underline{P}\left(\mathrm{Cl}_{t}^{\leq}\right)$; iv) possible $D_{\leq}$-decision rules generated from the $\underline{P}\left(\mathrm{Cl}_{t}^{\leq}\right)$, with or without any ambiguity; and v) approximate $D_{\leq>}$-decision rules generated from $P$-boundaries, representing doubtful knowledge. Thus, this method creates a set of decision rules based on a training table and, additionally, a training map. To build the table, we selected a subset of ROs to be assigned to only one class $\mathrm{Cl}_{t}$ according to its vulnerability level. All evaluations for choosing ROs were made in a GIS environment to avoid the use of tables. To achieve decision rules, DomLEM algorithms (Blaszczynski et al., 2013) were used and extracted from the jMAF platform.

\section{Preference learning in dominance-based rough set approach}

In this study we applied the PL-DRSA for the decision rules (Figueiredo and Mota, 2019), which allows new information to update the decision rules. The process analyses the quality of the rules to create an aggregated set that can be updated so that it accounts for the evolution in the number of COVID-19 cases. In this way, it can be discovered whether or not there are changes in the vulnerability class cardinalities.

Decision rules must first be obtained for each set of ROs. They are called instances $(j)$, each of which has a set of ROs $\left(a_{i, j}\right)$, and each is associated with a unique decision class. Let $R^{I j}$ be the set 
of rules for each instance; $a_{i, j} \in A$ an object belonging to the information base that will be sorted in $C l_{t, j}$; and $\varphi$ the function that returns the set of criteria belonging to the decision rules for each instance:

$\varphi: R_{j}^{I} \times A \longrightarrow R_{j}^{I}$

$R_{j}^{I} \times a_{i, j} \rightarrow\left\{r_{t}^{I j}, t \in\{1 \ldots n\}\right\}$

where $n$ is the number of rules of the classification; $\mathrm{r}\left(I_{j}, a_{i, j}, C l_{t, j}\right)$ a classification at the $a_{i, j}$ by $I_{j}$ on approximation of unions $C l_{t, j}$ (resp. $\left.\mathrm{Cl}_{t, j}\right)$; then $\underline{P}\left(\mathrm{Cl}_{t, j}\right)\left(\operatorname{resp} \underline{P}\left(\mathrm{Cl}_{t, j}\right) \mathrm{T}\right.$. Let $r_{t}^{l j}$ be part of the rule that originated from the $R^{I j}$ set of the instance $I_{j}$ and $C$ the finite set of criteria. The function that returns a set of criteria contained in the premise of a rule is called $v$ :

$v: R_{j}^{I} \rightarrow C$

$r_{t}^{I j} \rightarrow\left\{c_{i}, i \in\{1 \ldots m\}\right\}$

where $m$ is the number of criteria from $C$ that forms part of the rule $r_{t}^{I j}$.

Redundant decision rules were identified. This happens when, given two parts of the rules, it is observed that:

$r_{t^{\prime}}^{I j} \subseteq r_{t^{\prime \prime}}^{I j+1}, \forall j \in J$

an assumption which generates a semantic conflict, which defines what rule must be used such that:

i. If $f\left(a_{i, j} c_{i}\right) \geq r_{t^{\prime}}^{I j}$ Then $a_{i, j} \in C l_{t, j}^{Z}$

ii. If $f\left(a_{i, j+1}, c_{i}\right) \geq r_{t^{\prime \prime}}^{I j+1}$ Then $a_{i, j+1} \in C l_{t, j+1}^{\gtrless}$; (2) $\forall i=1, \ldots, n$

with $r_{t^{\prime}}^{I j} \geq r_{t^{\prime \prime}}^{I j+1}, \forall j \in J \forall t \in T$

An approach to dealing with this type of case is to eliminate the redundancy that may occur in the rules. Then, after verifying what is happening with $r_{t^{\prime}}^{I j} \subseteq r_{t^{t^{\prime \prime}}}^{I j+1}, \forall j \in J$ the rule is removed using a smaller range. In the situation above, for condition ii of rule, there is the options to exclude the redundant part or to change the examples to represent situations of $C l_{t}$, thus obtaining new results for $\mathrm{Cl}_{t, j}^{t}$ (resp. $\left.\mathrm{Cl}_{t, j}^{-}\right)$.

\section{Identifying environmental risk factors for COVID-19}

The first two confirmed cases of COVID-19 and 17 suspected cases in Pernambuco were recorded on 12 March 2020. Two months later, the state had recorded almost 26,000 confirmed cases and 2,000 deaths due to this infection (Ministry of Health, 2020). We conducted a preliminary analysis of the first three months of the pandemic (March to May 2020), gathering data from three different stages: the beginning, the peak and the decreasing phase.

Due to the recent discovery of COVID-19, there are still few studies on environmental risk factors in Brazil. Thus, we preselected variables to characterize vulnerability in the municipalities on studies that explore factors used to analyse the evolution of transmission rates (Liu, 2020; Requia et al., 2020; Zhai et al., 2020). As a result, we selected the following determinants: the number of cases, the size of the population of the municipality and that of the urban area. Primary data were taken from the Brazilian demographic census (IBGE, 2020) and a subset of variables was calculated with the aid of GIS: i) small communities located in the rural area of some municipalities, represented by the number of residences (range 10-20); ii) total territorial area of the municipalities (in $\mathrm{km}^{2}$ ); iii) total estimated population in the municipality according to IBGE (2020); iv) size of the economically active population (in number); v) ratio of those economically active to the total population (employment rate); vi) population density in the municipalities per $\mathrm{km}^{2}$; vii) urban area in the municipalities (in $\mathrm{km}^{2}$ ). Towns far away from metropolitan regions have small such areas.

\section{Process development}

We determined these relationships by correlating available COVID-19 data with the set of variables presented above. We chose eight different days with cumulatively recorded cases of COVID-19 as dependent variables of ordinary least squares (OLS). The results can be found in Table 1 . For all variables, the models for each day analysed explain more than $98 \%$ of recorded COVID19 cases in the municipalities investigated. The results also confirm that risk factors are related to the evolution of the disease in the municipalities.

Additionally, all variables were submitted to GWR (Table 2) considering the same dates as those in Table 1 . The bandwidth presented the same results for the eight days, which suggested that there is the same degree of smoothing in the model between days. Also, the spatial autocorrelation of GWR residuals resulted in nonsignificant Moran's I outcomes, thus implying little evidence of any autocorrelation in them. AIC, multiple $\mathrm{R}^{2}$ and adjusted $\mathrm{R}^{2}$ presented some values similar to the OLS results, which implies that there is no significant difference between these models.

Additionally, we used IDW for spatial interpolation of the confirmed cases of COVID-19, considering two specific dates (12 May and 19 May) in order to predict a value for any unmeasured location. This resulted in a density map (Figure 3 ) over the region indicating where the incidence of cases was at its most intense.

This visual inspection was useful to guide the process of selecting ROs when building the GIS-MCDA model based on the PL-DRSA. We compared the results of the COVID-19 vulnerability maps with the IDW results of confirmed cases of COVID-19 in different periods to support the construction of the learning map.

\section{Geographical information system-multiple-criteria decision aid model to identifying vulnerable areas: training}

To accurately analyse the spread of COVID-19, we added the following condition attributes: the total number of cases; the num-

Table 1. Ordinary least squares analysis.

\begin{tabular}{lccc} 
Month-Day & AIC & Multiple $R^{2}$ & Adjusted $^{2}$ \\
$03-12$ & 1027.560 & 0.9920 & 0.992 \\
$03-27$ & 14.346 & 0.9920 & 0.992 \\
\hline $04-06$ & 591.520 & 0.9880 & 0.988 \\
$04-18$ & 1385.885 & 0.9890 & 0.989 \\
\hline $04-27$ & 1703.319 & 0.9890 & 0.989 \\
$05-09$ & 2239.514 & 0.9690 & 0.991 \\
\hline $05-12$ & 1984.754 & 0.9900 & 0.989 \\
$05-19$ & 2325.030 & 0.9736 & 0.989 \\
\hline
\end{tabular}

AIC, Akaike's information criterion. 
ber of cases per 100,000 inhabitants; and the weekly rate of COVID-19 expansion. The latter analysis obviously requires data from two separate days: i) first-day registered cases (registered cases 1); ii) second-day registered cases (recorded cases 2); iii) growth of the number of cases between first and second date (Rate_Day1_Day2); iv) first-day number of cases per 100,000 inhabitants (1); v) second-day number of cases per 100,000 inhabitants (2). Since the peak of the first wave in Pernambuco occurred in May, we began the analysis by considering two specific dates in this period, i.e. 12 and 19 May. Table 3 shows the descriptive statistics of the attributes, whose type (maximization/gain and minimization/cost) were set according to the relationships indicated in the OLS and GWR models based on the number of confirmed cases of COVID-19. These attributes were used to choose the ROs (from the municipalities of the state of Pernambuco) so that the demographic factors, i.e. the characteristics of the space and rate of disease evolution, could be analysed simultaneously by the DRSA. Three preference-ordered classes of vulnerability level were established $C l=\left\{C l_{t}, t \in T\right\}$ with $T=\{1, \ldots 3\}$ : one area with low $\left(C l_{1}\right)$; one with moderate $\left(\mathrm{Cl}_{2}\right)$; and one with high vulnerability $\left(\mathrm{Cl}_{3}\right)$.

The variables shown in Table 3 were used to classify each of the ROs into $\mathrm{Cl}_{t}$. For the initial analysis, the days of 12 and 19 May were considered. Nine sample instances consisting of ROs were obtained with reference to these days. Other variables included were the number of inhabitants; the number of confirmed cases; the evolution of the disease (rate of spread); and the size of the urban area in each municipality. The GIS interface was used to conduct this analysis in order to make the process more understandable. For each instance, a set of ROs was selected to be assigned to the classes of vulnerability. Figure 4 shows the nine instances of ROs, using the notation I Day1_Day2_Number of the instances. Red represents the RO assigned to the most vulnerable

Table 2. Geographically-weighted regression analysis.

\begin{tabular}{lcccccc} 
Month-Day & Bandwidth & Multiple $\mathbf{R}^{2}$ & Adjusted R & AIC & Moran's I & P-value \\
$03-12$ & 4.50 & 0.9925 & 0.9921 & 1069.913 & -0.009332 & 0.641506 \\
$03-27$ & 4.50 & 0.9932 & 0.9928 & 5428.000 & -0.003721 & 0.836681 \\
\hline $04-06$ & 4.50 & 0.9894 & 0.9888 & 585.980 & -0.001390 & 0.627943 \\
$04-18$ & 4.50 & 0.9895 & 0.9890 & 1384.968 & -0.003773 & 0.841979 \\
\hline $04-27$ & 4.50 & 0.9897 & 0.9892 & 1701.397 & -0.003721 & 0.836681 \\
$05-09$ & 4.50 & 0.9903 & 0.9800 & 2066.666 & -0.0014 & 0.434300 \\
\hline $05-12$ & 4.50 & 0.9906 & 0.9901 & 1981.788 & -0.005434 & 0.999932 \\
$05-19$ & 4.50 & 0.9908 & 0.9904 & 2133.577 & -0.003844 & 0.847831 \\
\hline
\end{tabular}

AIC, Akaike's information criterion.
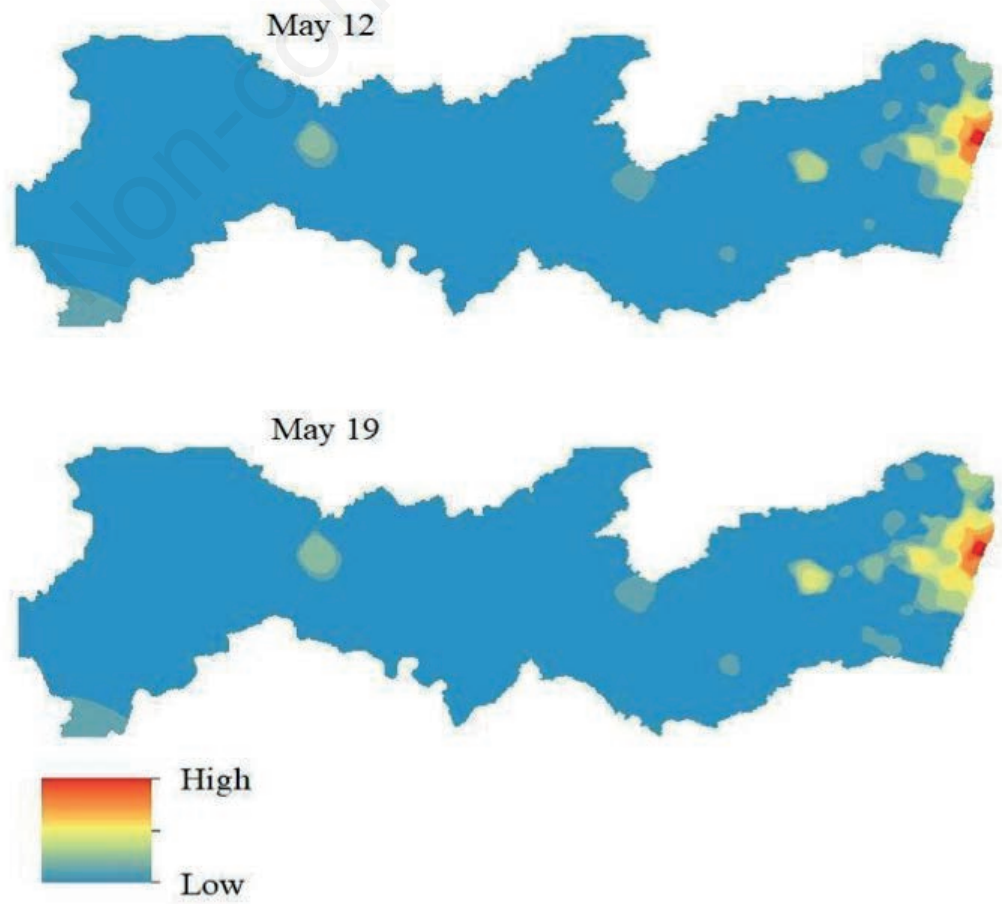

Figure 3. Inverse distance weighting analysis of COVID-19 cases. 
class, while low vulnerability is represented by blue.

Figure 5 shows the distribution of class in terms of unions of decision classes $\mathrm{Cl}_{t}$ and $\mathrm{Cl}_{t}{ }_{t}$ (i.e. based on the approximations 'Least' and 'Most'). It can be observed a similar result for all instances in terms of class cardinality. For all instances, the selected ROs gave most support at the union of classes of type 'Least moderate' and 'Most moderate', while the 'Least high' received fewer objects. Thus, a similar distribution can be seen. Table 4 presents other measures related to the Reducts and Core, with reducts being the minimal subset of attributes capable to sort objects with the same quality and core being the intersection of all reducts. We observed that all the instances of quality of approximation $=1$ and
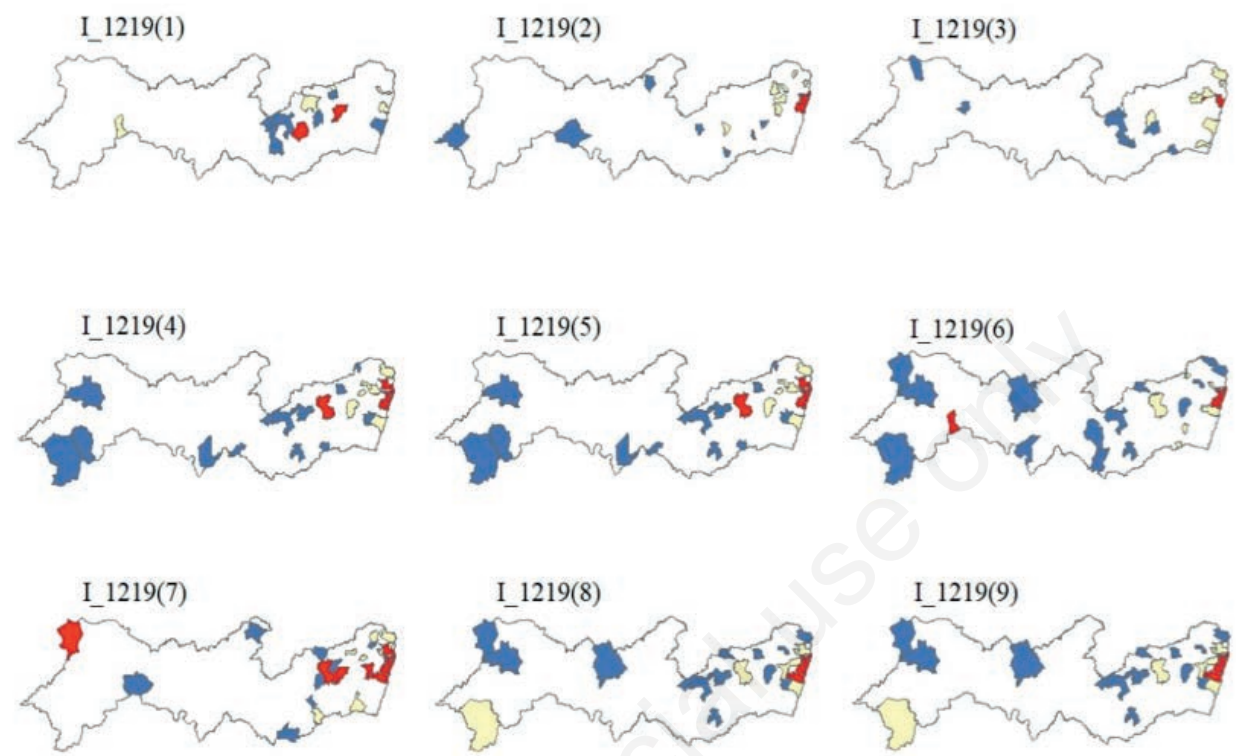

Low vulnerability

Moderate vulnerability

High vulnerability

Figure 4. Reference objects.

Table 3. Difference between the municipalities: descriptive statistics of the attributes.

\begin{tabular}{|c|c|c|c|c|c|c|}
\hline Criterion & Code & Maximum & Minimum & Mean & SD & Type \\
\hline Small communities & S_Comu & 32.00 & 0.00 & 2.10 & 3.21 & Gain \\
\hline Municipality area & A_Mun & $4,561.87$ & 25.70 & 532.88 & 685.99 & Cost \\
\hline Municipality population & Pop & $1,645,727.00$ & $4,548.00$ & $51,923.97$ & $139,647.26$ & Gain \\
\hline Employed population & Em_Pop & $717,517.00$ & 310.00 & $9,383.86$ & $54,202.15$ & Gain \\
\hline Employed population rate & Em_Pop_RT & 0.49 & 0.04 & 0.10 & 0.07 & Gain \\
\hline Density & Den & $9,503.20$ & 8.43 & 267.59 & 964.62 & Gain \\
\hline Urban area & U_area & 222.76 & 0.61 & 15.34 & 30.60 & Cost \\
\hline Registered cases 1 & RC_0512 & $3,656.00$ & 0.00 & 38.11 & 280.05 & Gain \\
\hline Registered cases 2 & RC_0519 & $4,710.00$ & 0.00 & 51.66 & 362.89 & Gain \\
\hline Rate_Dayl Day2 & RT_12_19 & 4.33 & 0.00 & 0.43 & 0.64 & Gain \\
\hline Number of cases per 100,000 inhabitants 1 & RT_0512 & 222.15 & 0.00 & 18.14 & 31.40 & Gain \\
\hline Number of cases per 100,000 inhabitants 2 & RT_0519 & 286.20 & 0.00 & 27.35 & 42.46 & Gain \\
\hline
\end{tabular}

SD, standard deviation.

Table 4. Dominance-based rough set approach parameters used for the nine instances. I_1219(1) I_1219(2) I_1219(3) I_1219(4) I_1219(5) I_1219(6) I_1219(7) I_1219(9) I_1219(9)

$\begin{array}{lcccccccccc}\text { Reducts } & 3 & 10 & 16 & 39 & 39 & 33 & 7 & 26 & 26 \\ \text { Core } & 0 & 0 & 0 & 0 & 0 & 0 & 2 & 0 & 0\end{array}$


the accuracy of approximation in the union of classes also $=1$, thus indicating that most instances were suitable for obtaining precise classification (i.e. without ambiguity) of the ROs. Those results show the strength of using decision rules in classifying the municipalities in the region taking the corrected assignment of ROs as a measure of consistence (for each instance). Thus, the ROs for each instance explain the decision classes. However, it is necessary to guarantee that other alternatives classified by the decision rules maintain reality.

\section{Preference learning dominance-based rough set}

The decision rules generated by the DRSA by means of the learning map helps classifying the overall alternatives, here the municipalities with respect to levels of vulnerability. To avoid misrepresentation of reality (which is one the potential outcomes) our proposed methodology comprises an interactive learning procedure. This is implemented by several instances to update the set of ROs, and thus increase the ability to infer the vulnerability of all municipalities. Each instance generates a set of decision rules relative to a RO subset. Figure 6 present the results for nine instances. Note that most of the municipalities were assigned as low vulnerability ones. To obtain the decision rules, we considered a level of consistency equal to 1 and a union of class of the monotonic type to induce decision rules. We established the parameters of the type certain for the induction of rules by means of DRSA. As a result the procedure sorts the alternatives into low, moderate and high

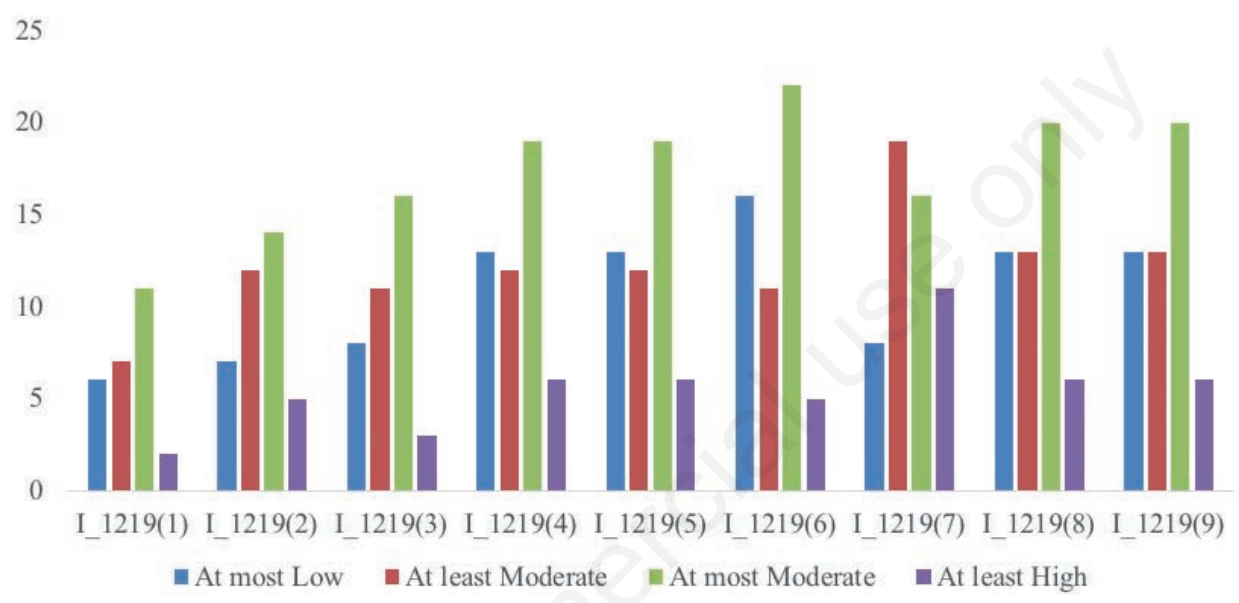

Figure 5. Distribution of class by union approximation for the nine instances.
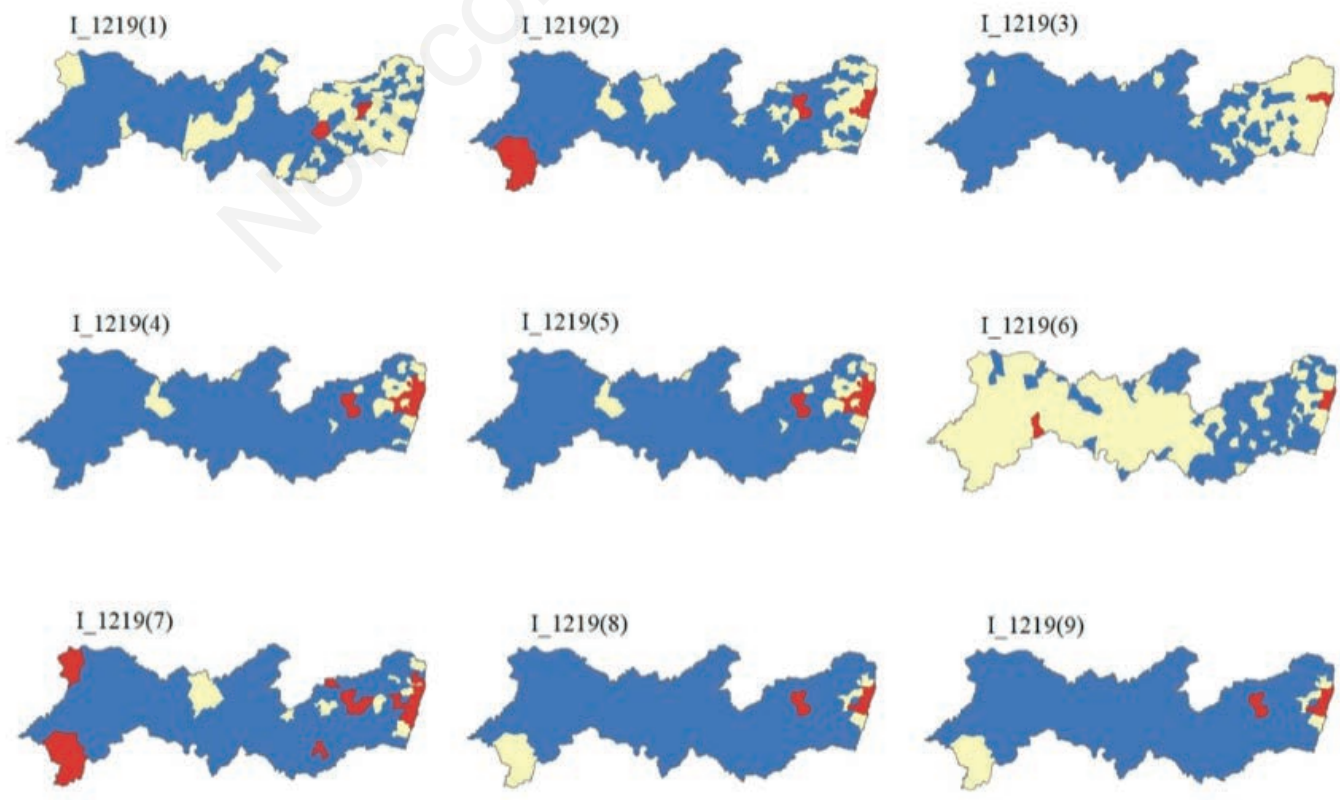

Low vulnerability

Moderate vulnerability

High vulnerability

Figure 6. Vulnerability level for COVID-19 in nine instances. 
vulnerability. The model can be run in an ArcGIS system in combination with the jMAF software in an interactive way that generates a map with vulnerability classifications using the preference model based on decision rules.

\section{Results}

In relation to the three urban zones (MRR, Caruaru and Petrolina) there were some interesting observations. Most of the MRR municipalities maintained at a high vulnerability level for all instances, with the exception of the I_1219(1) instance. The Caruaru zone had high vulnerability in six instances: I_1219(2), I_1219(4), I_1219(5), I_1219(7), I_1219(8) and I_1219(9), the Petrolina zone high vulnerability in I_1219(2) and I_1219(7), while the other municipalities were classified as moderate or of low vulnerability. The decision rules induced presented a goodness fitness index to sort the municipalities. It is important to highlight that most of the MRR municipalities served as ROs when creating the instances.

We compared the results of nine instances (Figure 6) and the result of the IDW for the confirmed cases of COVID-19 (Figure 3) for both dates. We observed similarities between them, e.g. the IDW surface was consistent with the outcome produced by the decision rules, in which the results achieved in instances: I_1219(2); I_1219(5); I_1219(6), and I_1219(7) could better represent the situation. We observed that all municipalities had been sorted into three vulnerability classes for the four best instances of the ROs based on decision rules. Table 5 describes the decision rules for instances: I_1219(2); I_1219(5); I_1219(6) and I_1219(7)

Table 5. Decision rules for the datasets: $I \_1219(2)$; $I \_1219(5) ; I \_1219(6)$ and $I \_1219(7)$.

\begin{tabular}{|c|c|c|c|c|}
\hline $\begin{array}{l}\text { I_1219(2) } \\
\text { Objects (no.) }\end{array}$ & Rule (ID) & Description of rule & Class & Supporting objects (no.) \\
\hline 19 & $\begin{array}{l}1 \\
2 \\
3 \\
4\end{array}$ & $\begin{array}{l}\text { Pop } \geq 157,828 \\
\text { RC_1205 } \geq 7 \\
\text { RC_1205 } \leq 1 \\
\text { Pop } \leq 83,641\end{array}$ & $\begin{array}{l}\text { At least } 3 \\
\text { At least } 2 \\
\text { At most } 1 \\
\text { At most } 2\end{array}$ & $\begin{array}{l}5 \\
12 \\
7 \\
14\end{array}$ \\
\hline $\begin{array}{l}\text { I_1219(5) } \\
\text { Objects (no.) }\end{array}$ & Rule (ID) & Description of rule & Class & Supporting objects (no.) \\
\hline 25 & $\begin{array}{l}1 \\
2 \\
3 \\
4 \\
5 \\
6 \\
7\end{array}$ & $\begin{array}{l}\text { RC_1905 } \geq 78 \\
\text { RC_1205 } \geq 18 \\
\text { RT_1205 } \geq 27.11 \\
\text { RC_1205 } \geq 16 \& \text { RC_905 } \geq 27 \\
\text { RC_1205 } \leq 17 \& \text { RT_905 } \leq 28.25 \\
\text { RC_1205 } 15 \& \text { RT_1205 } \leq 21.78 \\
\text { RC_1905 } 62\end{array}$ & $\begin{array}{l}\text { At least } 3 \\
\text { At least } 2 \\
\text { At least } 2 \\
\text { At least } 2 \\
\text { At most } 1 \\
\text { At most } 1 \\
\text { At most } 2\end{array}$ & $\begin{array}{l}6 \\
10 \\
9 \\
10 \\
12 \\
11 \\
19\end{array}$ \\
\hline $\begin{array}{l}\text { I_1219(6) } \\
\text { Objects (no.) }\end{array}$ & Rule (ID) & Description of rule & Class & Supporting objects (no.) \\
\hline 27 & $\begin{array}{l}1 \\
2 \\
3 \\
4 \\
5 \\
6 \\
7 \\
8 \\
9 \\
10 \\
11 \\
12 \\
13\end{array}$ & $\begin{array}{l}\text { Den } \geq 2,714.47 \\
\text { U_area } \leq 1.3 \\
\text { RC_1205 } \geq 44 \\
\text { A_Coun } \leq 110.82 \& \text { RC_1205 } \geq 2 \\
\text { U_area } \leq 3.31 \& \text { RC_1205 } \geq 1 \\
\text { RT_1905 } \leq 10.42 \\
\text { Em_Pop } \leq 0.044 \\
\text { RT_1219 } \leq 0.69 \& \text { RT_1905 } \leq 15.74 \\
\text { A_Count } \geq 503.95 \& \text { U_area } \geq 201.48 \\
\text { A_Coun } \geq 445.89 \& \text { RT_1219 } 0.63 \\
\text { RC_1205 } \leq 18.0 \& \text { RT_X1219 } 0.39 \\
\text { A_Coun } \geq 885.99 \\
\text { RC_1205 } 126.0 \& \text { RT_1219 } \leq 1\end{array}$ & $\begin{array}{l}\text { At least } 3 \\
\text { At least } 3 \\
\text { At least } 3 \\
\text { At least } 2 \\
\text { At least } 2 \\
\text { At most } 1 \\
\text { At most } 1 \\
\text { At most } 1 \\
\text { At most } 1 \\
\text { At most } 1 \\
\text { At most } 1 \\
\text { At most } 2 \\
\text { At most } 2\end{array}$ & $\begin{array}{l}4 \\
1 \\
7 \\
4 \\
3 \\
11 \\
1 \\
11 \\
1 \\
7 \\
10 \\
9 \\
21\end{array}$ \\
\hline $\begin{array}{l}\text { I_1219(7) } \\
\text { Objects (no.) }\end{array}$ & Rule (ID) & Description of rule & Class & Supporting objects (no.) \\
\hline 27 & $\begin{array}{l}1 \\
2 \\
3 \\
4 \\
5 \\
6 \\
7 \\
8 \\
9 \\
10\end{array}$ & $\begin{array}{l}\text { RC_1205 } \geq 44 \\
\text { RT_1219 } \geq 4.33 \\
\text { S_Comum } \geq 2.0 \& \text { Pop } \geq 84,418 \\
\text { EM_pop } \geq 7836 \\
\text { U_area } \leq 7.18 \\
\text { S_Comu } \leq 0 \text { \& RC_1905 } \leq 11 \\
\text { Pop } \leq 48,554.0 \& \text { U_area } \geq 10.49 \\
\text { Pop } \leq 48,554 \\
\text { Pop } \leq 79,758.0 \& \text { RT_1219 } \leq 0.63 \\
\text { S_Comu } \leq 1 \text { \& Em_Pop } \leq 12,958\end{array}$ & $\begin{array}{l}\text { At least } 3 \\
\text { At least } 3 \\
\text { At least } 3 \\
\text { At least } 2 \\
\text { At least } 2 \\
\text { At most } 1 \\
\text { At most } 1 \\
\text { At most } 2 \\
\text { At most } 2 \\
\text { At most } 2\end{array}$ & $\begin{array}{l}9 \\
1 \\
3 \\
13 \\
6 \\
2 \\
7 \\
14 \\
10 \\
8\end{array}$ \\
\hline
\end{tabular}


so that the MRR mostly had a high vulnerability level (I 1219(2), I 1219(5) and I 1219(7)) or moderate vulnerability (I_ 1219(6)). Only Petrolina varied between low (I_1219(5)), moderate (I_1219(7)) and high vulnerability (I_1219(2), I_1219(7)), although it recorded 17 COVID-19 cases on May 12 and 22 on May 19.

Every decision rule specifies the recommended vulnerability level for COVID-19 cases and the reasons why that level was suggested. For every rule, it is also possible to know which ROs supported that rule. However, we highlighted only the number of objects supporting each rule. The decision rules can be read as follows: for rule 2, if the population (pop) is greater than or equal to 157,828 than the object would be sorted into the least, Class 3 . The other decision rules should be interpreted in a similar way.

The results for the first instance I_1219(2) obtained four decision rules (for approximation of decision class) and there were 19 ROs. The vulnerability levels can be explained by the attributes of the recorded cases - 12 May (RC-1205) and the population number. Although these rule sets produced a good quality of fitness index, we considered it weak, especially if applied in isolation (separately from other instances) to sort the overall municipalities into vulnerability levels. With respect to I_1219(5) we noticed that all conditional attributes considered only cases of COVID-19 represented by the following attributes: RC_0519, RC_0512, RT_0512 and RT_0519. The onset of I_1219(6) consisted of 27 ROs and 13 decision rules, and thus more municipalities could be assigned to a moderate vulnerability level. However, a few municipalities were assigned as high vulnerability. Comparatively, I_1219(7) decision rules produced a result closer to reality (current scenario), which indicated that the municipalities with a large number of confirmed cases were more vulnerable. The MRR, was all high vulnerability and the level of vulnerability of the other municipalities as shown in Figure 6.

Table 6 presents municipalities per vulnerability class for the selected four instances analysed. The number of municipalities with high vulnerability varied between 8 and 15. All the four instances kept the following municipalities in high vulnerability: Recife (the state capital), Cabo de Santo Agostinho, Camaragibe, Jaboatão dos Guararapes and Olinda. All of these municipalities belong to the MRR. Caruaru was also classified at the high and moderate vulnerability. The other municipalities varied between moderate and low vulnerability.

In the training phase, we included a procedure to select the instances to be used. Notice that when DRSA results (Figure 6) and IDW analysis (Figure 3) are compared, the results can be seen to be satisfactory, although only four instances were selected: I_1219(2), I_1219(5), I_1219(6) and I_1219(7). Using the PLDRSA, we observed a similar distribution of the municipalities across the categories of vulnerability (Table 6) compared to the concentrations of the confirmed cases of COVID-19. It was noted that five municipalities were always considered within the high vulnerability level. As of 19 May these five municipalities had accumulated a total of 7473 confirmed COVID-19 cases $(78.6 \%$ of all cases in Pernambuco at the time), together accounting for 3 million inhabitants $(33.8 \%$ of the population of Pernambuco). Thus, the larger the population of a region the more rapidly the virus spreads.

Regarding the low and moderate vulnerability municipalities, there were 166 municipalities assigned to these levels, due to the instance decision rules considered. On 12 May there were 618 recorded cases and on 19 May 379 new cases had been added. As expected, urban places thus were a risk factor for the propagation of the virus. Also, in 26 municipalities, any additional confirmed cases were reported on 19 May. Besides, on 12 May, the mean number of cases was 0.11 per 1000 inhabitants, which increased to 0.18 on 19 May. In municipalities with a population above 50,000, these means were 0.46 (12 May) and 0.66 (19 May). Thus, the increase in number of cases is low in municipalities with a small populations.

\section{Revealing vulnerable areas by preference learning dominance-based rough set}

PL-DRSA allows updating the vulnerability results to account for the evolution of the number of COVID-19 cases, or even to include new condition attributes. We eliminated redundant decision rules, combining only decision rule sets from qualified instances, which enabled analysis of new examples. In this study, we updated data regarding the number of cases, but social and economic variables remained the same. Therefore, the changes were made for: Recorded cases 1 (Day_1); Recorded cases 2 (Day_2); Rate of cases (RT_Day1_Day2); Number of cases per 100,000 inhabitants (Day_1); and Number of cases per 100,000 inhabitants (Day_2).

After consolidating the decision rules, we evaluated five different dates, starting in July and ending in November 2020: 1 July 01 and 7 July; 20 July and 27 July; 6 August and 12 August; 28 August and 3 September; 1 November and 7 November. Table 6 presents the consolidated decision rules. The condition part of the instances was allocated and separated by connector OR. Figure 7 presents the results considering the decision rules consolidated for each period.

Regarding the analysis applied for new cases (after the training tests) there were two distinct moments, which covered the months of July, August and September 2020. The first represented a reduction in the incidence of the disease in the whole state. The second, also called the second wave, was characterized by a sharp increase in new cases starting in November 2020 resulting in an insupportable situation at the health care institutions. In July, the mean number of new cases in the state was 3.58, with numbers above 30 only in the (MRR area). In August and September, we observed a few regions of high vulnerability, as a result of the growth of the number of new cases in particular areas. In November, however, new cases appeared in most of the municipalities.

Table 6. Classification of the municipality vulnerability.

\begin{tabular}{lcccc} 
Level & I_1219(2) & I_1219(5) & I_1219(6) & I_1219(7) \\
Low & 141 & 151 & 103 & 159 \\
Moderate & 35 & 22 & 75 & 10 \\
\hline High & 8 & 11 & 6 & 15 \\
\hline
\end{tabular}


We applied an interactive learning approach in which we explored the model using different instances in the training phase. We included a procedure to select the instances to be used as a learning procedure to build the rules. The rules were then updated to represent the situation presented in Figure 7. It was noted that the model was capable to classify the municipalities in a consistent way, considering the updated data of new cases and the sociodemographic condition. We also observed that the virus spread more rapidly within municipalities with larger populations. For instance, in November 2020, in these municipalities, there was a mean rate of cases greater than $40 \%$ and an accumulated total of 126,339 confirmed COVID-19 cases, represented by $21 \%$ of all municipalities but $59 \%$ of the total population.

\section{Discussion}

The detailed nature of the coronavirus pandemic and for how long it will pose a major threat to society remain uncertain. The pandemic has incurred various adverse impacts on people's lives and on the economy. Thus, the present study makes use of a preference learning method to induce decision rules to support decision-making policies to control and reduce the number of new cases of infections by actions such as social distancing and, in extreme cases, lockdown.

The GIS-MCDM model was found to be satisfactory for classifying municipalities according to their level of vulnerability to COVID-19, considering registered of new cases and other vari-
July 01 and July 07

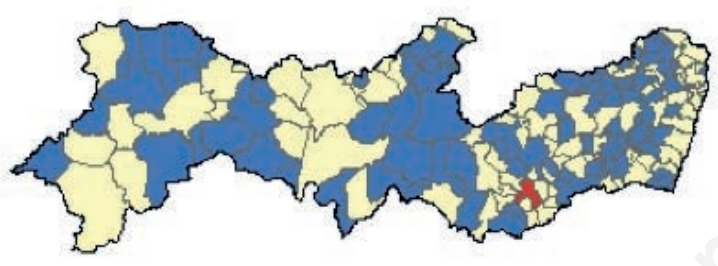

August 06 and August 12

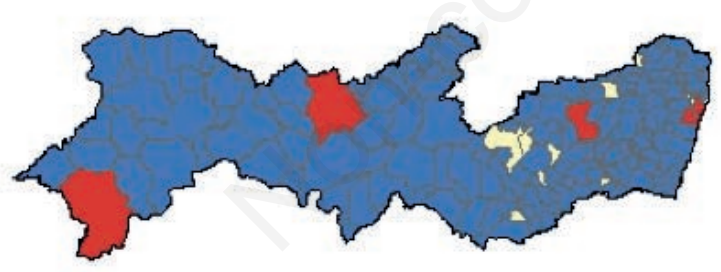

July 20 and July 27

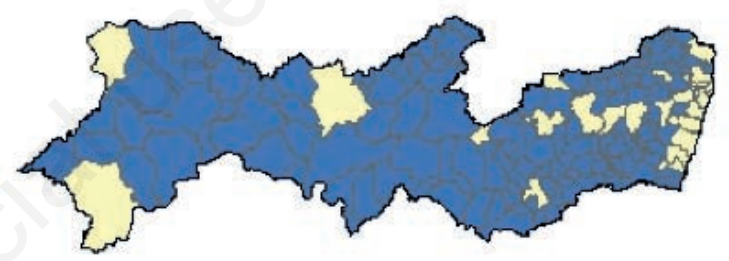

Aug ust 28 and September 03

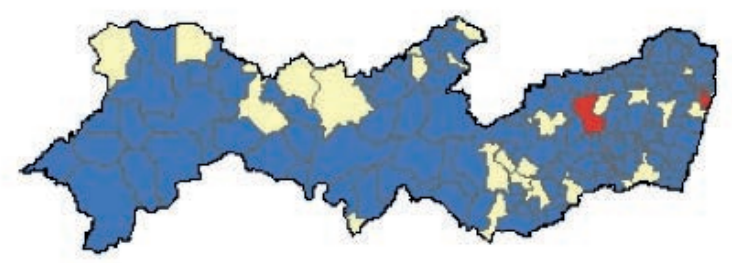

November 01 and November 07

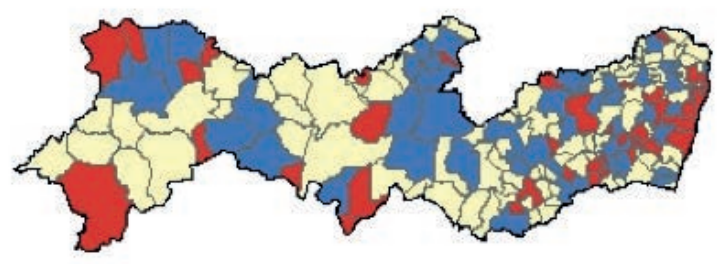

Low vulnerability $\square$ Moderate vulnerability $\square$ High vulnerability

Figure 7. Vulnerable analysis for updating the recording of cases. 
ables (social, economic and demographic) representing the characteristics of the municipality. It is important to note that preventive or responsive management decisions also influences the level of vulnerability of each municipality, reinforcing the dynamic nature of this study. As an example, an increasing number of cases were observed from October to November 2020, represented by a relaxation in social distancing restrictions (in November, there were elections for mayors and councillors, in Brazil).

Several studies have pointed out vulnerable areas using mapping tools for cases of COVID-19 (Ye and Hu, 2020; Han et al., 2021), trend estimations (Coelho et al., 2020) and investigations on the determinants of COVID-19 across different regions (Maciel et al., 2020; Andersen et al., 2021), while other authors have focussed on deprivation indicators (Maciel et al., 2020; Adersen et al., 2021). Our results confirm that populous areas and high-density areas are associated with higher transmissions rates and the proposed methodology has the advantage of considering multiple attributes that should help to guide decision-making related to actions against COVID-19 by means of a holistic learning approach based on maps. It avoids the effort needed to define model parameters, such as weights or preference thresholds, as required in most traditional MCDM methods, and we were able to identify areas vulnerable to COVID-19 using decision rules derived from a set of attributes of recorded cases, rates and risk factors.

From the perspectives of public policies and social distance rules, preventive measures have been considered. Also, there is a need to implement well-targeted policies tailored to support the return of economic activities. A study in Recife (Silva et al., 2020) verified a decreasing trend in cases after a strict quarantine had been imposed, compared to daily deaths in the absence of this intervention. To avoid the spread of the virus, it is imperative to identify and prioritize preventive actions for each risk group more effectively. The extracted rules and the vulnerability levels may be used to guide public policies decisions regarding the COVID-19 cases, as they consider the spatial characteristic of each municipality. Our model highlights the norm used for classification by means of the decision rules. Moreover, it can classify municipalities with distinct characteristics at the same level of vulnerability. For example, the level 'high', contains municipalities with more than 100,000 inhabitants as well as municipalities with less than 20,000 inhabitants. However, as it would be beyond the scope of this paper, we did not associate management actions with vulnerability levels, such as imposing restrictions, including quarantine measures (Singh et al., 2020), provision of new health services, economic support, incentives, educational and training programs.

Classification was not related to identifying and recommending specific measures of prevention. It is an application of a dataset used as criteria to guide how to categorize municipalities according to vulnerability levels. Also, the application of this model needs to be run constantly since the data should be updated as closely as possible to real time. Other relevant factors could also be added to the model, such as population morbidity issues and obesity. We also did not use hospital data and the results from testing for COVID-19. Such information could be usefully considered in future studies on aiding management decisions.

\section{Conclusions}

We propose the GIS-MCDA approach to identify and sort areas vulnerable to COVID-19, based on a multicriteria learning approach and spatial visualization. The main contribution and innovation of this study concerns two matters. First, the proposed methodology reveals the set of attributes and condition rules that mostly impact the levels of vulnerability. Second, the methodology identifies the municipalities that are the most vulnerable to the spread of COVID-19, based on a combined spatial data analysis and a holistic preference learning decision model.

\section{References}

Adger WN, 2006. Vulnerability. Global Environ Chang 16:268-81. Adhikari Meng S, Wu YJ, Mao YP, Ye RX, Wang QZ, Sun C, Sylvia S, Rozelle S, Raat H, Zhou H, 2020. Epidemiology, causes, clinical manifestation and diagnosis, prevention and control of coronavirus disease (COVID-19) during the early outbeak period: a scoping review. Infect Dis Poverty 9:29.

Ambikapathy B, Krishnamurthy K, 2020. Mathematical modelling to assess the impact of lockdown on COVID-19 transmission in India: model development and validation. JMIR Public Health Surveill 6:e19368.

Andersen LM, Harden SR, Sugg MM, Runkle JD, Lundquist TE, 2021. Analyzing the spatial determinants of local COVID-19 transmission the United States. Sci Total Environ 754:1-10.

Aquino EML, Silveira IH, Pescarini JM, Aquino R, Souza-Filho JA, Rocha AS, Ferreira A, Victor A, Teixeira C, Machado DB, Paixão E, Alves FJO, Pilecco F, Menezes G, Gabrielli L, Leite L, Almeida MCC, Ortelan N, Fernandes QHRF, Ortiz RJF, Palmeira RN, Junior EPP, Aragão E, Souza LEPF, Netto MB, Teixeira MG, Barreto ML, Ichihara MY, Lima RTRS, 2020. Social distancing measures to control the COVID-19 pandemic: potential impacts and challenges in Brazil. Ciência Saúde Coletiva 25:2423-46.

Ball F, Neal P, 2002. A general model for stochastic SIR epidemics with two levels of mixing. Math Biosci 180:73-102.

Bekiros S, Kouloumpou D, 2002. SBDiEM: A new mathematical model of infectious disease dynamics Chaos, Solitons Fractals 136:1-16.

Blaszczynski J, Greco S, Matarazzo B, Slowinski R, Szelag M, 2013. jMAF Dominance-based rough set data analysis framework. In: Skowron A, Suraj Z (Eds.), Rough sets and intelligent systems. Professor Zdzislaw Pawlak in memoriam, Springer, Berlin Heidelberg.

Brazilian Institute of Geography and Statistics, 2020. IBGE Cidades 2020 [Demographic census 2010]. Available from: https://cidades.ibge.gov.br/

Coelho FC, 2020. Assessing the spread of COVID-9 in Brazil: mobility, morbidity and social vulnerability. PLoS One 15:1-11.

Crokidakis N, 2020. COVID-19 spreading in Rio de Janeiro, Brazil: Do the policies of social isolation really work? Chaos, Solitons \& Fractals 136:1-17.

De Toro P, Nocca F, Renna A, Sepe L, 2020. Real estate market dynamics in the city of Naples: an integration of a multi-criteria decision analysis and geographical information system. Sustainability 12:1-24.

Djilali S, Ghanbari B, 2020. Coronavirus pandemic: a predictive analysis of the peak outbreak epidemic in South Africa, Turkey, and Brazil. Chaos, Solitons \& Fractals 138:1-20.

Dom NC, Ahmad AH, Latif ZA, Ismail R, 2016. Application of geographical information system-based analytical hierarchy process as a tool for dengue risk assessment. Asian Pacif J Trop 
Dis 6:928-35.

Edler C, Schröder AS, Aepfelbacher M, Fitzek A, Heinemann A, Heinrich F, Klein A, Langenwalder F, Lütgehetmann M, Meißner K, Püschel K, Schädler J, Steurer S, Mushumba H, Sperhake JP, 2020. Dying with SARS-CoV-2 infection - an autopsy study of the first consecutive 80 case in Hamburg, Germany. Int J Legal Med 19:1-10.

ESRI, 2011. ArcGIS Desktop: Release 10. Environmental Systems Research Institute, Redlands, CA, USA.

Figueiredo CJJ, Mota CMM, 2019. Learning preferences in a spatial multiple criteria decision approach: an application in public security planning. Int J Inf Technol Decis Making 18:1403-32.

Fotheringham A, Brunsdon C, Charlton M, 2002. Geographically weighted regression: the analysis of spatially varying relationships. John Wiley \& Sons, Chichester, UK.

Fusade-Boyer M, Pato PS, Komlan M, Dogno K, Batawui K, GoMaro E, McKenzie P, Guinat C, Secula A, Paul M, Webby RJ, Tran A, Waret-Szkuta A, Ducatez MF, 2020. Risk mapping of influenza D virus occurrence in ruminants and swine in Togo using a spatial multicrieria decision analysis approach. Viruses 128:1-12.

Grassly NC, Fraser C, 2006. Seasonal infectious disease epidemiology. Proc R Soc Bull 273:2541-50.

Greco S, Ehrogott M, Figueira J (Eds.), 2016. Multiple criteria decision analysis: state of the art surveys. Springer, New York, NY, USA, pp. 507-555.

Greco S, Matarazzo B, Slowinski R, 2002. Rough sets methodology for sorting problems in presence of multiple attributes and criteria. Eur J Operat Res 138:247-59.

Greco S, Słowiński R, Zielniewicz P, 2013. Putting dominancebased rough set approach and robust ordinal regression together. Decis Support Syst 54:891-903.

Han Y, Yang L, Jia K, Li J, Feng S, Chen W, Zhao W, Pereira P, 2021. Spatial distribution characteristics of the COVID-19 pandemic in Beijing and its relationship with environmental factors. Sci Total Environ 761:1-11.

Hazarika N, Barman D, Das AK, Sarma AK, Borah SB, 2018. Assessing and mapping flood hazard, vulnerability and risk in the Upper Brahmaputra River valley using stakeholders' knowledge and multicriteria evaluation (MCE). J Flood Risk Manage 11:S700-16.

Hongoh V, Hoen AG, Aenishaenslin C, Waaub J-P, Bélanger D, Michel P, The Lyme-MCDA Consortium, 2011. Spatially explicit multi-criteria decision analysis for managing vectorborne diseases. Int J Health Geograph 70:1-10.

Jain S, Sharma T, 2020. Social and travel lockdown impact considering coronavirus disease (COVID-19) on air quality in megacities of India: present benefits, future challenges and way forward. Aerosol Air Qual Res 20:1222-36.

Jelokhani-Niaraki M, Malczewski J, 2015. The decision task complexity and information acquisition strategies in GIS-MCDA. Int J Geograph Inf Sci 29:327-44.

Kim SJ, Bostwick W, 2020. Social vulnerability and racial inequality in COVID-19 deaths in Chicago. Health Educ Behav 47:509-13.

Li J, Wang J, Wu C, Yang Y, Ji Z, Wang H, 2007. Establishment of a risk assessment framework for analysis of the spread of highly pathogenic avian influenza. Agric Sci China 6:877-81.

Liu L, 2020. Emerging study on the transmission of the novel coronavirus (COVID-19) from urban perspective: evidence from China. Cities 103:1-11.
Linka K, Peirlinck M, Costabal FS, Kuhl E, 2020. Outbreak dynamics of COVID-19 in Europe and the effect of travel restrictions. Comput Meth Biomechan Biomed Engine. [Epub ahead of print] doi:10.1080/10255842.2020.1759560.

Ministry of Health, 2020. Banco de dados do Sistema Único de Saúde-DATASUS [Database system unified health - DATASUS]. Available from: http://www.datasus.gov.br

Moran PAP 1950. Notes on continuous stochastic phenomena. Biometrika 37:17-23.

Moreira RS, 2020. COVID-19: intensive care units, mechanical ventilators, and latent mortality profiles associated with casefatality. Brazil Cadern Saúde Públ 36:1012.

Pedrosa NL, Albuquerque NLS, 2020. Spatial analysis of COVID19 cases and intensive care beds in the State of Ceará, Brazil. Ciência Saúde Colet 25:2461-8.

Qi X, Wang J, Li X, Wang Z, Liu Y, Yang H, Li X, Shi J, Xiang H, Liu T, Kawada N, Maruyama H, Jiang Z, Wang F, Takehara T, Rockey DC, Sarin SK; COVID-Cirrhosis-CHESS Group, 2020. Clinical course of COVID-19 in patients with pre-existing decompensated cirrhosis: initial report from China. Hepatol Int 22:1-5.

Qiu Y, Chen X, Shi W, 2020. Impacts of social and economic factors on the transmission of coronavirus disease 209 (COVID19) in China. J Popul Econ 33:1127-72.

Requia W, Kondo EK, Adams MD, Gold DR, Struchiner CJ, 2020. Risk of the Brazilian health care system over 5572 municipalities to exceed health care capacity due to the 2019 novel coronavirus (COVID-19). Sci Total Environ 730:139144.

Silva L, Figueiredo Filho D, Fernandes, A 2020. The effect of lockdown on the COVID-19 epidemic in Brazil: evidence from an interrupted time series design. Cadernos Saúde Públ 36:e00213920.

Singh RK, Rani M, Bhagavathula AS, Sah R, Rodriguez-Morales AJ, Kalita H, Nanda C, Sharma S, Sharma YD, Rabaan AA, Rahmani J, Kumar P, 2020. Prediction of the COVID19 pandemic for the top 15 affected countries: advanced autoregressie integrated moving average (ARIMA) model. MIR Public Health Surveill 6:1-23.

Souza DB, Santos FA, Figueiroa E, Correia JB, da Silva HP, de Lima Filho JL, Albuquerque J, 2020. Using curvature to infer COVID-19 fractal epidemic network fragility and systemic risk. medRxiv 2020.04.01.20047225.

Stevens KB, Gilbert M, Pfeiffer DU, 2013. Modeling habitat suitability for occurrence of highly pathogenic avian influenza virus $\mathrm{H} 5 \mathrm{~N} 1$ in domestic poultry in Asia: A spatial multicriteria decision analysis approach. Spatial Spatial-temp Epidemiol 4:1-14.

UNISDR, 2009. Terminology on disaster risk reduction. UNISDR, Geneva, Switzerland.

Watson DF, Philip GM, 1985. A refinement of inverse distance weighted interpolation. Geoprocessing 315-27.

WHO (World Health Organization), 2020. Coronavirus disease (COVID-2019) situation reports. Available from: https:/www.who.int/emergencies/diseases/novel-coronavirus2019/situation-reports Accessed: May 15, 2020.

Yang X, Yu Y, Xu J, Shu H, Xia J, Liu H, Wu Y, Zhang L, Yu Z, Fang M, Yu T, Wang Y, Pan S, Zou X, Yuan S, Shang Y, 2002. Clinical course and outcomes of critically ill patients with SARS-CoV-2 pneumonia in Wuhan, China: a single-centered, retrospective, observational study. Lancet Respir Med 8:475-81.

Ye L, Hu L, 2020. Spatiotemporal distribution and trend of 
COVID-19 in the Yangtze River Delta region of the People's Republic of China. Geospatial Health 15:1-8.

Younsi FZ, Hamdadou D, Chakhar S, 2018. A multicriteria spatiotemporal system for influenza epidemic surveillance. In: Dey N (Ed.), Technological innovations in knowledge management and decision support. IGI Global Press, Hershey, PA, USA, pp. 176-202.

Younsi F, Chakhar S, Ishizaka A, Hamdadou D, Boussaid D, 2020.
A dominance-based rough set approach for an enhanced assessment of seasonal influenza. Risk Analysis 40:1323-41.

Zhai W, Liu M, Peng Z, 2020. Social distancing and inequality in the United States amid COVID-19 outbreak. Econ Space 0:1-3.

Zifu F, Hong S, Lihua W, 2015. Research of the classification model based on dominance rough set approach for China emergency communication. Math Probl Engine 1-8. 